\title{
MISCELLANEA
}

\section{A Case of Cirrhosis and Primary Carcinoma of the Liver in Chronic Industrial Arsenical Intoxication}

\author{
S. S. JHAVERI* \\ From Victoria Hospital, Accrington, Lancashire
}

(RECEIVED FOR PUBLICATION JUNE 20, 1958)

A case of primary liver carcinoma associated with liver cirrhosis in a man who had handled arsenious oxide and sodium arsenite for over 20 years is described with reference to his occupational history, clinical condition, and with details of pathological findings.

Arsenical poisoning may occur in industry, in three forms: (1) From inhalation of or contact with dust of inorganic compounds, (2) from inhalation of arseniuretted hydrogen, (3) from contact with organic arsenic compounds. The inorganic compounds act as local irritants to the skin and mucosa and may have a carcinogenic effect. Arseniuretted hydrogen acts as a haemolytic agent and organic arsenic compounds as vesicants. The hepatotoxic action of inorganic arsenic compounds such as potassium arsenite, which is contained in Fowler's solution, has long been recognized by those using this solution as a therapeutic agent but has been scarcely mentioned as an industrial hazard. Skin cancer constitutes a well recognized occupational hazard.

The occurrence of hydrops and ascites following the ingestion of arsenic was first recorded by Bang in 1774 . Hutchinson (1895) was apparently the first to report that cirrhosis and ascites can be due to prolonged administration of arsenic and to draw attention to its carcinogenic properties. Since then, many cases suggesting arsenic as an aetiological agent in cirrhosis of the liver have been published. It is almost disregarded today when considering the aetiology of portal cirrhosis.

\section{Case Report}

A.T., aged 46, was first admitted on November 18, 1950. His work had entailed contact with an inorganic arsenic compound (sodium arsenite) for about 18 years. He was employed on different parts of the process from time to time and finally was the foreman in charge of the arsenic plant. The process consists of mixing white arsenic (arsenious oxide) with soda-ash (crude sodium bicarbonate) in a heated bath of water. The solution is pumped to a concentration tank where it is highly concentrated by heat. The liquor from this tank passes into a reverberating furnace where it is dried to form lumps of sodium arsenite. This is raked from the furnace into a barrow. The lumps are then ground in a mill to a fine

*Present address: Burnley Group of Hospitals, Burnley, Lancs. powder and mixed with mathylens blue. There are usually three men employed: one shovels white arsenic and soda-ash into the tank, the second is in charge of the furnace and rakes the material when it is dry, and the third is in charge of the grinding mill and fills the drums with the finished product. A.T. was employed in any of these processes. The men usually wore protective masks of unknown design and gloves. His alcohol consumption was an occasional pint of beer and, rarely, spirits.

Ten days before his admission he had pneumonia and while he was recovering he noticed rapidly increasing, painless, abdominal swelling. There was no significant previous history. He was afebrile (pulse $90 \mathrm{~min}$., regular, B.P. $130 / 80 \mathrm{~mm}$. $\mathrm{Hg}$ ). There was no oedema of the feet. The tongue was coated and the throat congested. The abdomen was tense and uniformly distended with fluid. Superficial abdominal veins were dilated. Palpation of viscera was not possible. Other systems revealed nothing abnormal. The urine contained no albumin or sugar. Blood examination showed $\mathrm{Hb} 100 \%$, erythrocytes 5 million/c.mm.; leucocytes 7,000 (normal differential count) and E.S.R. $8 \mathrm{~mm}$./hour. The ascitic fluid had a specific gravity of 1020 , proteins $6 \%$, a few lymphocytes, no malignant cells, and was negative in culture. Plasma proteins were $6.48 \mathrm{~g} . \%$. A chest radiograph on November 20,1950 , showed elevation of both domes of the diaphragm but no focal lesion. A 24-hour specimen of urine examined by the Forensic Science Laboratory, Preston, contained $0.13 \mathrm{mg}$. of arsenious oxide (equivalent to 0.86 p.p.m. arsenious oxide).

He was treated with a low-salt diet, mercurial diuretics, streptomycin, and paracenteses. He was discharged on January 2, 1951, and returned to his work with arsenic.

He was well until February 13, 1956, when he was re-admitted on account of acute abdominal pain and vomiting of one day's duration. Exploratory laparotomy revealed enormously thickened parietal peritoneum, adherent coils of bowel, and cirrhosis of the liver. Postoperative chest radiographs showed migratory pneumonia and he was treated with penicillin and streptomycin. $\mathrm{He}$ was discharged on February 28, but did not return to work.

Seven days before his last admission on October 3, 1957 , he noticed puffiness of the face and rapidly increasing swelling of the abdomen. There was no history of haematemesis, jaundice, or bleeding per rectum. He was pale, oedematous, and puffy. The skin showed mottled brownish pigmentation, chiefly in covered areas. The skin of the palms and soles was markedly thickened. $\mathrm{He}$ was afebrile (pulse $90 \mathrm{~min}$., B.P. $120 / 80 \mathrm{~mm}$. Hg.). The abdomen was very tense and swollen with fluid, but there was no fluid thrill or shifting dullness. Superficial abdominal veins were engorged and visible. Viscera were not palpable. Rectal and proctoscopic examina- 
tions revealed noabnormality. Other systems were normal.

The urine contained no albumin or sugar. A blood examination showed $\mathrm{Hb} 78 \%$; leucocytes 8,700 c.mm. (normal differential count), E.S.R. $4 \mathrm{~mm} . /$ hour, total serum proteins 4.9 g. $\%$ (albumin 2.3 g. $\%$; globulin, $2.6 \mathrm{~g} . \%$ ) and urea $48 \mathrm{mg}$. \%. Liver function test results were: alkaline phosphatase 10 units, thymol turbidity, 1 unit, zinc turbidity 5 units, serum bilirubin $0.7 \mathrm{mg}$. $\%$, direct and indirect Van den Bergh tests negative. Ascitic fluid: sp. gr. 1030 , proteins $8 \cdot 28 \mathrm{~g}$. $\%$, mesothelial cells and few polymorphs, no malignant cells, culture negative. Blood group A rhesus negative. Serum chlorides 94 mEq. per litre; sodium $128 \mathrm{mEq}$. per litre; potassium 3.9 mEq. per litre. A chest radiograph showed loss of translucency at the right base, suggesting a recent inflammatory lesion. A cardiovascular outline was within normal limits; the oesophagus showed evidence of varicosities.

The Forensic Science Laboratory, Preston, reported as follows:

A. Hair, total weight $0 \cdot 1379$ g., 209 p.p.m. of arsenious oxide

B. Nail clippings, total weight 0.0390 g., 564 p.p.m. of arsenious oxide

C. Skin biopsy, total weight $0 \cdot 1402$ g. Arsenic not detected.

He was treated with a low-salt diet, mercurial diuretics, and parenteral vitamins, but the oedema gradually increased. Twelve days after admission he developed vertigo and became apathetic, disorientated, and confused. Flapping tremors were detected once. He was put on a "liver failure régime" but his condition gradually deteriorated, and he became deeply comatose. On October 19 he had two haematemeses (about 2 to $4 \mathrm{oz}$.), Next day he developed pulmonary oedema and died.

\section{Necropsy Report}

Dr. R. D. Popham reported as follows: "Body of a male aged about 45 years. He was well nourished with gross oedema of the trunk and legs and a distended abdomen. Rigor mortis was absent. There was marked hypostatic cyanosis. The surface of the body showed blotchy, greyish-brown pigmentation of the skin of the trunk, upper arms, and legs. There were many small spider naevi and hyperkeratotic thickening of the skin of the hands and feet. There was a healed left paramedian surgical incision. No other scars or injuries were detected. The pericardium was normal. The heart was normal in size and weighed $300 \mathrm{~g}$. The myocardium was flabby and pale but there was no hypertrophy or infarction. The foramen ovale was closed and all valves were normal. There was slight atheroma of the aorta and coronary arteries. A partly thickened thrombus was present in the splenic vein. The pleural cavities were obliterated by thick fibrous adhesions. Both lungs weighed approximately $800 \mathrm{~g}$. and showed some emphysema with slight oedema and gross venous congestion. There was thickening of the parietal and visceral peritoneum and the whole of the intestine formed a mass bound together by dense fibrous adhesions. This mass was adherent to the other viscera. The liver, spleen, and stomach were covered by thick peritoneum of the "sugar icing" type. The liver weighed $1,400 \mathrm{~g}$. Its capsule was smooth and thickened as above. The cut surfaces showed very little remaining liver tissue, its place being taken by multiple nodules of varying size of white carcinomatous tissue. The liver tissue seen was fibrous. The spleen was congested and fibrous and weighed $400 \mathrm{~g}$. The pancreas was normal. The stomach contained fresh and altered blood. Three flat superficial ulcers, each about $1 \mathrm{~cm}$. diameter, were present on the posterior wall. Varices of gastric and oesophageal veins were present. The intestines were slightly distended but there was no obstruction. The small intestine contained altered blood. The mesenteric glands were normal, except for one small calcified gland. The generative organs were normal and the prostate was not enlarged. The capsules of the kidneys were not adherent and both renal cortex and medulla were normal. The suprarenals were normal. The brain weighed 1,300 g. and showed slight venous congestion. The cause of death was haemorrhage from oesophageal varices, and primary carcinoma of the liver with plastic peritonitis. The histopathological section of liver confirmed the diagnosis of cirrhosis with primary carcinoma."

\section{Discussion}

Although arsenic is commonly met with in industry only eight cases of chronic arsenical poisoning were reported during the years 1950 to 1954 (Chief Inspector of Factories, 1955).

Arsenic determinations on normal human urine are quoted by Cox (1925) as varying between 0 and $0.7 \mathrm{mg}$. of arsenious oxide per litre, the commonest figures being $\mathbf{0 . 0}$ to $\mathbf{0 . 2} \mathrm{mg}$. per litre. More recently, Sultzaberger (1943) reported values of about $0.03 \mathrm{mg}$. per litre and Kingsley and Schaffert (1951) quoted a range between 0.046 and $0.206 \mathrm{mg}$. per litre. The results of the radioactivation method carried out by Smales and Page (1952) showed a range from 0.013 to $0.33 \mathrm{mg}$. of arsenic per $\mathrm{kg}$. of urine, which is within the range quoted by Cox. There are many reports on the arsenic content of hair. For example, Szép (1940) examined hair and nail clippings and found that normal "healthy" levels were for hair, 0.27 to 0.77 p.p.m. and for nails, 1.5 to 5.2 p.p.m. Künkele (1940) considered that indications of arsenical poisoning were given by contents greater than 3 p.p.m. in head hair and $0.1 \mathrm{mg}$. per litre in the urine; results by the radioactivation method ranged from 0.51 to $2 \cdot 1$ p.p.m. for hair, from 0.82 to 3.5 for finger nails, and 0.52 to 5.6 p.p.m. for toe nails. A new modified method of polarographic estimation of arsenic in blood and urine was introduced by Naoyoshi, Norifusa Iwataki, and Toshikazu Yamamoto (1955) who found that the minimum amount of arsenic detectable was $0.5 \gamma$. A normal Japanese adult had 0 to $11.4 \gamma$ of arsenic per $100 \mathrm{~g}$. of blood and 0 to $28 \gamma$ per litre of urine, while workers in the arsenic industry were found to have $9 \cdot 2$ to $20.8 \gamma$ and 82 to $113 \gamma$ respectively.

The figures obtained in the case now reported were extremely high compared with "normal" arsenic levels and even with those published for workers in the arsenic industry. It is possible that "mechanically bound" 
arsenic, that is, on the surface of the hair and nail, was present.

Parker (1957) showed by analysing the necropsy findings that malignant change complicates cirrhosis oftener than is generally appreciated, particularly in the male. It has also been suggested by Sommers and McManus (1953) that multiple internal carcinomata may develop in chronic arsenical poisoning.

The clinical picture and positive laboratory findings showed that this patient was suffering from chronic arsenical poisoning. In the absence of other aetiological factors, arsenic appears to have been the cause of cirrhosis-carcinoma of liver.

I wish to express my thanks to Dr. W. A. L. MacFadyen for allowing me to publish this case report and for valuable criticism; Dr. R. D. Popham for the necropsy report; Dr. W. B. Waring for his help; Col. Backhouse, H.M. Coroner, for permission to publish the necropsy report, and to Miss M. Crabtree for secretarial help.

\section{REFERENCES}

Bang, F. L. (1774). " "De hydrope ex Ingestio Arsenico Observatio", Soc. Med. Havn. Coll., 1, 307.

Chief Inspector of Factories (1955). A Annual Report, 1954. H.M.S.O. London.

Cox, H. E. (1925). Analyst, 50, 3.

Hutchinson, J. (1895). Arch. Surg., Lond., 6, 389.

Kingsley, G. R., and Schaffert, R. R. (1951). Analyt. Chem., 23, 914.

Künkele, F. (1940). Chem. Z., 64, 29.

Naoyoshi, Ida, Norifusa Iwataki, and Toshikazu Yamamoto (1955). Chem. Abstr. 49, 1858e.

Parker, R. G. F. (1957). Proc. roy. Soc. Med., 50, 145.

Smales, A. A., and Page, B. D. (1952). Analyst, 77, 196

Sommers, S. C., and McManus, R. G. (1953). Cancer, 6, 347.

Sultzaberger, J. A. (1943). Industr. Engng Chem., Anal. Ed. 15, 408.

Szé, O. (1940). Hoppe-Seylers. Z. physiol. Chem., 267, 29.

\section{BOOK REVIEWS}

Le Otopatie da Rumore e Nozioni di Audiologia. By Vittorino Pescetti. (Pp. xii = 96; 17 figures. Lire 1,200.-.) Rome: Edizioni E.N.P.I. 1956.

This volume is No. 9 of a series of monographs on various aspects of the prevention of accidents and diseases in industry. It is published by the E.N.P.I. (National Organization for the Prevention of Accidents), a body concerned with industrial health services as well as accident prevention which makes available to industry all that we understand by these terms as well as specialist service in respect of any aspect of them. The E.N.P.I. is, in conception, a private, non-profit making concern, but has, in fact, become a para-state service with centres in Rome, Milan, Turin, and elsewhere. Its services include all aspects of safety organization, medical examination of workers, records, analysis of environmental contaminants, etc., which are paid for by industrial concerns on a per capita basis or some other arrangement. Its great advantage to the industrialist is that he simply hands over his problem to E.N.P.I. and need not bother about it any more unless a recommendation for improvement or change of plant, process, or environment, is sent to him. E.N.P.I. obtains doctors for industry and facilitates their operation.

Among its many activities the E.N.P.I. includes the publication of safety literature and posters, together with reviews of medical and safety subjects and monographs on specialized aspects of industrial medicine. By means of lectures, demonstrations, exhibitions, and symposia it maintains valuable contact and cooperation between state authorities, workers' organizations, medical associations, universities, and employers on manifold aspects of occupational health and safety.

The volume under review bears, to one who is acquainted with many of the personnel and methods of E.N.P.I., the stamp of that organization in that it embodies, with characteristic lack of prolixity, the fundamental and practical principles of audiometry and the pathology of noise as these affect or enter into the field of industrial medicine. It demonstrates the need in our work for monographs, of text-books not in the traditional model but consisting of groups of quasi-monographs.

We are not fully informed on the activities of industrial medical officers in this country in the field of measurement and control of noise in industry. The subject does not figure notably in our journals. In the U.S.A. and some European countries there is great interest in this field, and not only in those trades which are outstandingly noisy (boiler makers, metal workers, riveters, engine testers, aircraft mechanics, nail makers, users of pneumatic hammers, and others) but also in trades or jobs where it is not intensity (energy of sound measured in decibels) and frequency (number of cycles per unit time) or long-acting dissonances of high intensities but rather 